\title{
In Ifltemoriam.
}

\section{A TRIBUTE TO THE MEMORY}

OF

\section{H. MACNAUGHTON-JONES, M.D. ;} F.R.C.S.I., F.R.C.S. En.; Ex-Prof. of Onstetrics, Quenn's Collear, Cork.

Died on the 26th of April, 1918, at the Rest, 6 Ravenscroft Park, High Barnet, Middlesex, Henry MacnavghTON-JoNes, M.D., F.R.C.S.I. \& E., son of the late William Thomas Jones, M.D., of 65 Great George Street, Cork, aged 73 years.

Macnaughton-Jones' " Diseases of Women" having reached its ninth edition shows what a good head my late friend had. It is my privilege to record evidence of him also having had a good heart. A more generally beloved man I have never came across. He won the affection of all who knew him intimately. It was my good fortune to enjoy his close friendship for forty out of my fifty-four years in the Medical Profession.

No one could see Macnaughton-Jones dispensing the hospitality of his happy home, or feel the warm grasp of his hand as he welcomed, in his truly Irish fashion, every guest that crossed his threshold, without feeling "drawn" to him in no ordinary way. But these were not the only marks distinguishing " MAC" (as we always called him) from the ordinary run of one's (so-called) "friends." On this point I can speak with confidence, for I was intimately associated with him for more than twenty year's in the earlier days of the Irish Medical Schools and Graduates' Association. "MAC" was a hard-working and enthusiastic colleague, and no one holding office under him could fail to be spurred by his example to redoubled efforts. I deeply regret that he has been taken from us before his great desire was ac- 


\section{Eil ftemoriam.}

accomplished-namely, that the roll of the Irish Medical Schools' and Graduates' Association should include a thousand members. However, he died with the conviction on his mind-expressed to myself a few weeks ago-...that the remaining three hundred recruits would be obtained as soon as the war was over.

"MAC" set us all a good example of being to each others virtues very kind, and to their fáults-well!nearly blind. "MAC" was a critic, but I never heard him criticise in an unkindly way. He shrank always from hurting the feelings of anyone-above all any Irishman. The result of his influence in this direction was shown in the fact (stated the other day by Sir Launcelot Gubbins, when presiding at the autumn dinner of the Irish Graduates' Association) that, during the forty years of the existence of that society, there never was once even a whisper of a quarrel, albeit there were on the roll representatives of every shade of politics, and adherents of every form of religion. So much for the influence of the Mens medica and the example of such a man as Macnaughton-Jones.

Not only did he gather friends around him on every possible occasion, but he was able, by his slill, as a poet and elocutionist to supply them with draughts from the "Pierian spring." There is scarcely any quarter of the globe where Irish doctors have penetrated in which could not be found a copy of his "Piece of Delft and other Fragments," an extract from which charming book of poetry (entitled "Iife's Sunset") seems singularly prophetic :--

The setting sun was veiled behind a cloud

That half concealed the sinking globe of red;

Above, a shifting scene, of golden flood

With rainbow hues, the eastern sky o'erspread.

So sinks a life! Though clouds may partly dim

The light that it hath shed in days long past

It, like the sun, a new life will begin

And o'er its course fresh rainbow hues will cast. 


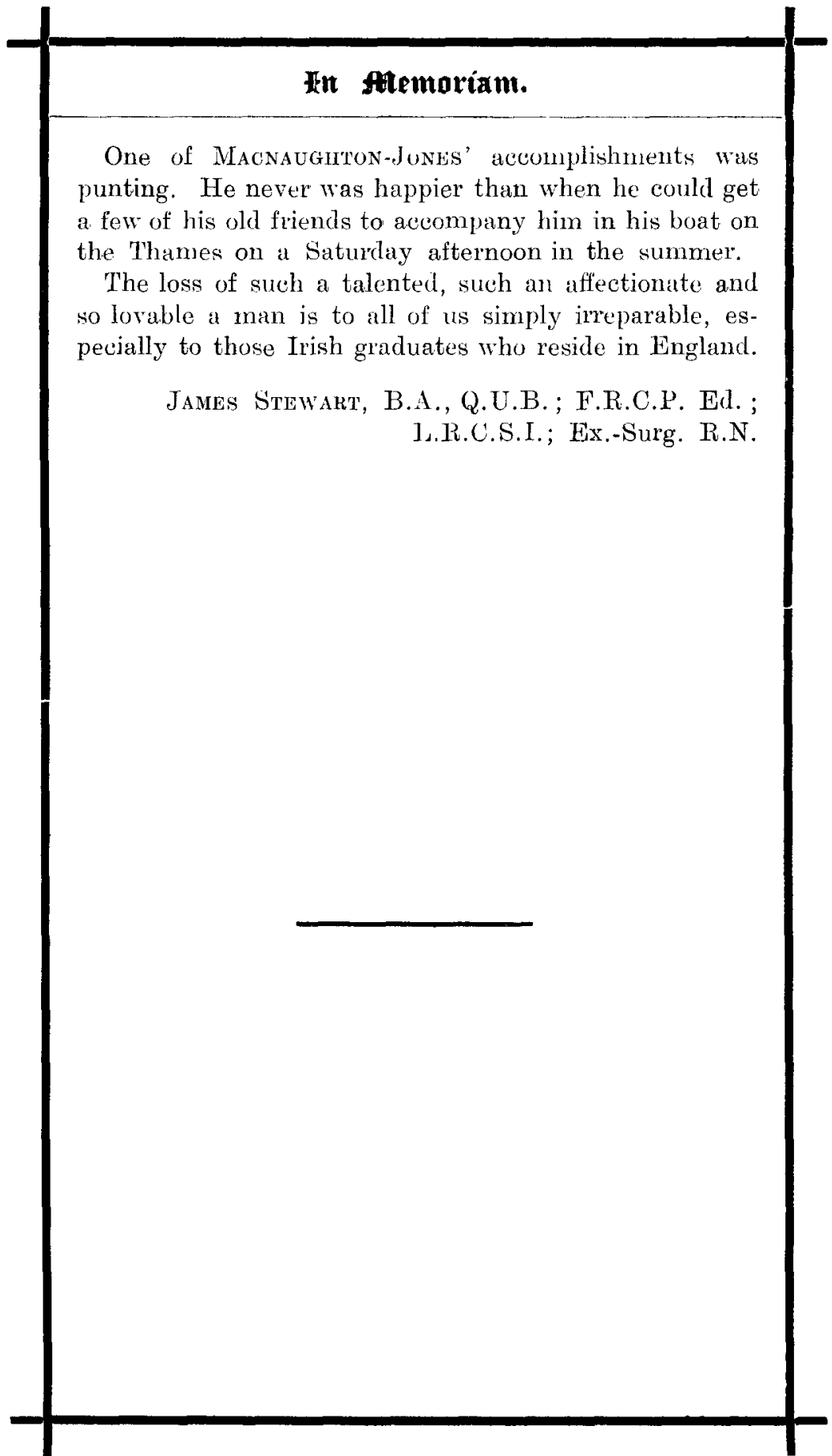

